\title{
Cerro Negro - Assessment of Beach Slope and Indetermination of the Operational Limits of Centrifugal Pumps
}

\author{
S. Barrera Arcadis Geotécnica, Chile \\ R. Hills Arcadis Geotécnica, Chile
}

\begin{abstract}
There currently exists a strong tendency to apply paste and thickened tailings technology to the management and deposition of tailings. This is particularly valid in the study of the 'Los Corralillos' Tailings Impoundment of the Cerro Negro iron mine, given the two intrinsic advantages of this technology: (i) location in an arid area in the North of Chile (where the water resource is very scarce) and (ii) an important potential in size reduction of the containment dam.
\end{abstract}

Due to the relative location between the plant and the impoundment and to the solids content level of the tailings at the plant, one of the most important aspects refers to the thickening stages and the location of the thickeners. For the analysis of alternatives for the tailings thickening and transport, as well as to estimate the deposition slope, a series of thickening tests, at a pilot scale, and laboratory rheology tests at the laboratory were performed using tailings slurry at various solid contents.

This paper describes the process performed focusing on two critical aspects such as: difficulties in determining the maximum level of slurry solid content that can be pumped by centrifugal pumps, and the estimate of the deposition slope based on results of the rheological tests. Finally, conclusions and recommendations of complementary studies are provided oriented at facilitating the key decisions.

\section{Introduction and objective}

Cerro Negro is an iron mine located on the southern border of the Atacama Desert, approximately $800 \mathrm{~km}$ north of Santiago, Chile (see Figure 1). This region is characterised by low precipitation and almost no vegetation except in the Copiapo Valley, located approximately $30 \mathrm{~km}$ from the mine. This valley has, economically-speaking, two main areas: (i) mining, and (ii) agriculture. The most relevant agricultural activity is the production of grapes for export. As a consequence, the agricultural activity competes with mining for the water resource which is very scarce and comes almost completely from snow melt off the Los Andes mountains.

The scarcity of the water resource has made it ever more necessary that the mining process diminish its consumption of 'fresh' water in order to obtain the environmental permits, reduce the dependence on sources (mostly groundwater wells), diminish investment costs to obtain water from other sources, and, finally, reduce the risk of running out of water.

Even though the mining companies are the owners of legal rights to the water, this does not mean they are allowed to avoid undertaking optimisation studies to reduce water losses, or the equivalent - of improving water reclaim in the floatation and tailings generation processes.

This paper presents the study performed for the tailings management at the Cerro Negro mine owned by Cia. Minera del Pacifico (CMP). This is where one of the critical aspects is presented by the design of a tailings impoundment that combines the following characteristics: (a) high water reclaim rate; (b) low investment and operational costs; and (c) the application of technology to minimise the risk. One of the critical aspects of this study is the estimate of the concentration limit of the tailings that allows them to be pumped by centrifugal pumps without risks. Another important aspect is the prediction of the tailings beach slope which affects the size of the dam embankment and the elevation of the ultimate discharge point. 


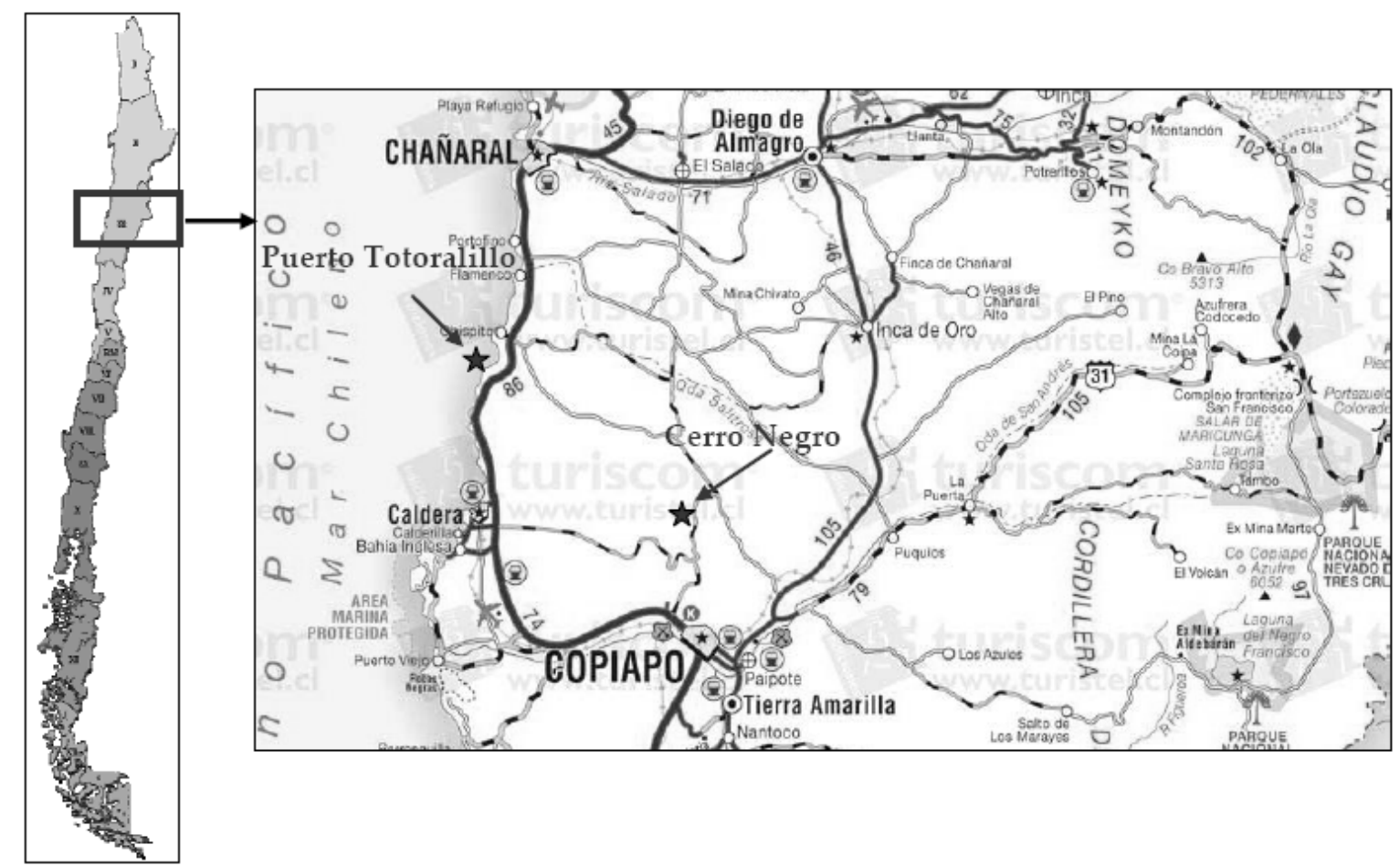

Figure 1 Cerro Negro mine location

\section{Iron tailings characterisation}

\subsection{Process characterisation}

- Average rate of tailings production: 13,874 tpd.

- Mechanical plant availability: $95 \%$.

- Variation in tailings deposition rate: $+/-15 \%$.

- Total tonnage to be deposited: 101.3 Mt (million tonnes).

\subsection{Tailings characterisation}

The characterisation of the tailings slurry was undertaken in laboratories of CETTEM (2008). The tailings samples were provided by Outotec, who were in charge of the pilot plant located in the facilities of the Pellet plant owned by CMP in Huasco. These samples corresponded to two types of thickening, according to the number of stages of the process. The tests performed were of three types:

- General characterisation of the tailings.

- Specific gravity of the solids.

○ Solids content by weight.

- Complete grain size analysis (sieves and laser diffraction of the fine fraction $\geq 1 \mu \mathrm{m}$ ).

$\circ \mathrm{pH}$.

- Transport.

- Complete rheology (rheogram).

- Deposition.

- Sedimentation tests (48 hour minimum). 
The results of the tests provided the following values:

- Specific gravity of solids:

$2.88 \mathrm{t} / \mathrm{m}^{3}$

- Dry density of deposition of tailings: $1.36 \mathrm{t} / \mathrm{m}^{3}$

- Grain size distribution of tailings:

$\mathrm{d}_{30}: 17 \mu \mathrm{m}$

$\mathrm{d}_{50}: 45 \mu \mathrm{m}$

$\mathrm{d}_{85}: 125 \mu \mathrm{m}$

- Rheology.

Table 1 Rheology tests outcomes

\begin{tabular}{llll}
\hline Case & $\begin{array}{l}\text { Type of } \\
\text { Fluid }\end{array}$ & Parameters & Origin \\
\hline $\begin{array}{l}\text { 1 (thickening in 1st stage, } \\
\mathrm{Cp}=70 \%)\end{array}$ & $\begin{array}{l}\text { Non } \\
\text { Newtonian }\end{array}$ & $\begin{array}{l}\mathrm{Ty}=55[\mathrm{~Pa}] \\
\mu_{\mathrm{B}}=0.058[\mathrm{~Pa} \mathrm{~s}]\end{array}$ & $\begin{array}{l}\text { Outotec, estimate for the sheared case } \\
\text { (passed by a agitation process) }\end{array}$ \\
$\begin{array}{l}\mathrm{C}(1 \mathrm{st} \text { stage of thickening, } \\
\mathrm{C}=40 \%)\end{array}$ & Newtonian & $\mu=0.015[\mathrm{~Pa} \mathrm{~s}]$ & CETTEM \\
$\begin{array}{l}\text { (1st stage of thickening, } \\
\mathrm{Cp}=50 \%)\end{array}$ & Newtonian & $\mu=0.016[\mathrm{~Pa} \mathrm{~s}]$ & CETTEM \\
$\begin{array}{l}\text { (1st stage of thickening, } \\
\mathrm{Cp}=60 \%)[*]\end{array}$ & Newtonian & $\mu=0.017[\mathrm{~Pa} \mathrm{~s}]$ & CETTEM \\
\hline
\end{tabular}

The analysis of this table indicates that there exists a transition from Newtonian to Non-Newtonian behaviour somewhere between 60 and $70 \%$ concentration, marked by the increase of the yield stress and Bingham viscosity.

- Tailings beach slope.

Because there are no special tests to predict the tailings beach slope, an approach based on the hydraulic and rheological behaviour of tailings was applied. This approach has been tested by Sofra and Boger (2001) and shows promising results. In this case the main assumptions are related to the pattern of the tailings flow when discharged in the deposit. Based on (i) the behaviour of tailings slurries in other deposits where slurry flows in canals are of a narrow width and (ii) the results of the laboratory tests; a sensitivity analysis was addressed to estimate tailings beach slope for different flow conditions and rheological parameters.

After an evaluation of the values obtained and considering the design purposes of the estimate, the deposition slope of the beach was estimated for tailings at $70 \%$ concentration, identifying two scenarios:

- Thickening in one stage: range between 0.9 to $2.1 \%$ with an average expected value of $1.2 \%$.

- Thickening in two stages: average expected slope value of $4.4 \%$ (without treatment at the discharge) and a minimum expected value of $2.1 \%$ with shear thinning treatment at the discharge.

\section{Trade-off analyses}

\subsection{General}

The general disposal scheme of tailings has the following basic units as shown in Figure 2:

- Concentrator plant.

- Tailings thickening and transport system between plant and impoundment.

- Los Corralillos tailings impoundment. 


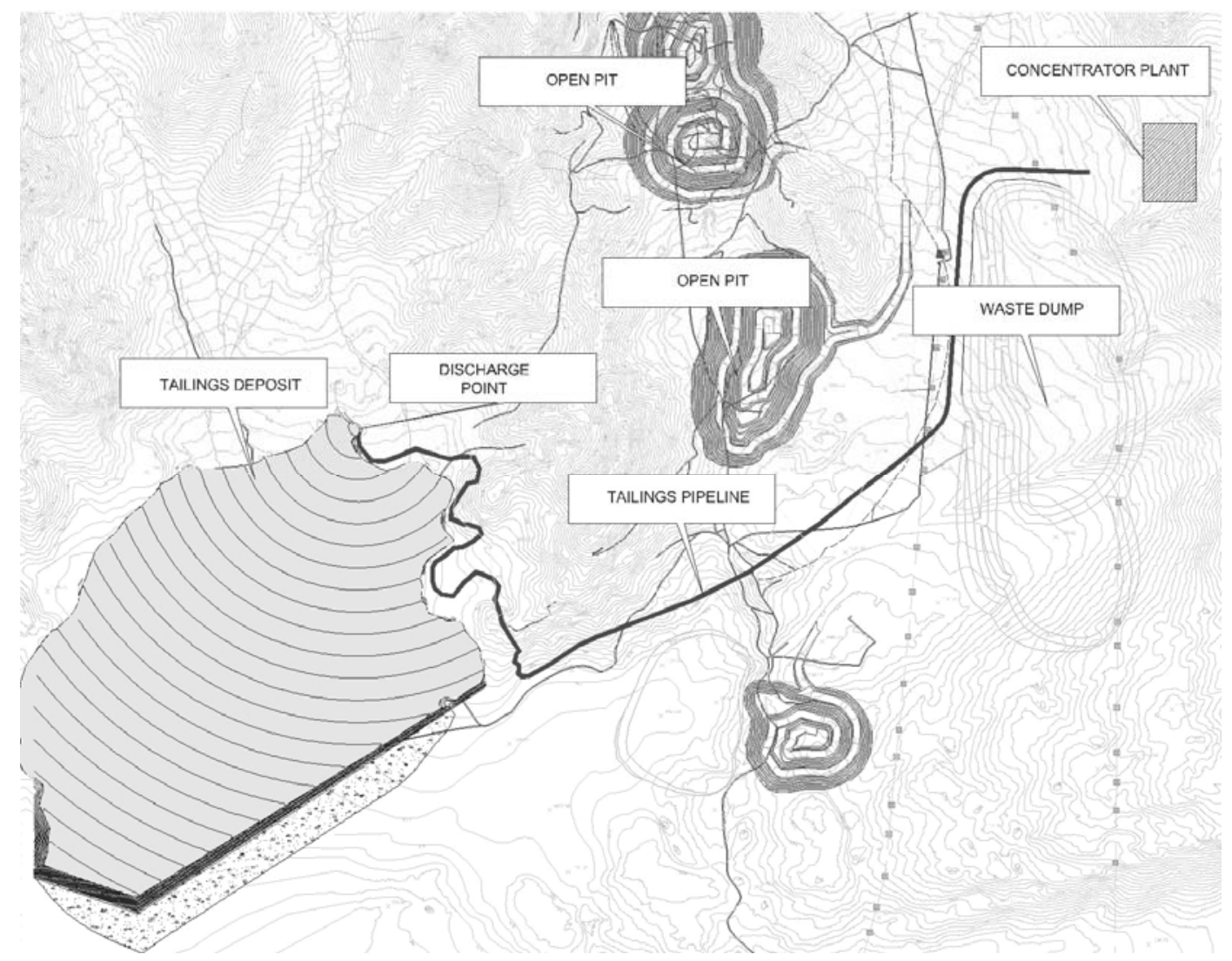

Figure 2 General layout - tailings management

The concentrator plant is located at the side of the mine and the tailings discharge is at elevation $1200 \mathrm{~m}$ a.s.l. The plant delivers tailings with a $4 \%$ concentration. There exist different alternatives to manage the thickening and transport of the tailings between the plant and the impoundment. In conditions where the tailings concentration is below $60 \%$, these tailings will flow by gravity to the rear area of the impoundment. In all of the alternatives, the tailings are finally discharged at a $70 \%$ concentration to the impoundment, forming a beach sloping in the direction of the dam, with the lowest point of the tailings surface being in contact with the dam. This dam is constructed in stages and by the downstream method, with waste rock from the mine transported directly by large tonnage trucks, placed in $2 \mathrm{~m}$ thick lifts, compacted by the heavy truck traffic. The upstream slope will be lined with a high density polyethylene (HDPE) geomembrane. Due to the thickened discharge, the formation of a permanent tailings pond inside the impoundment is not expected. However, under certain uncommon conditions, water may accumulate inside the impoundment. This water is reclaimed by two submersible, centrifugal pumps and an HDPE pipeline of $3.3 \mathrm{~km}$ in length. The Los Corralillos Tailings Impoundment has a water evacuation system that discharges excess water produced by heavy precipitation that surpasses the capacity of the impoundment. This system is formed by a lateral spillway, located on the left abutment of the dam and an evacuation canal excavated in rock.

The determination of the most convenient tailings thickening and transport alternative was analyzed through a technical-economical study that considered the following options:

- Alternative 1: Only one thickener located at the plant.

- Alternative 2: Thickened to $40 \%$ at the plant and thickened to $70 \%$ at the impoundment.

- Alternative 3: Thickened to $50 \%$ at the plant and thickened to $70 \%$ at the impoundment.

- Alternative 4: Thickened to $60 \%$ at the plant and thickened to $70 \%$ at the impoundment.

In all the cases, the concentrator plant is fixed and immovable for the study of alternatives. The tailings impoundment is also fixed insofar as its location, defined by the dam's axis, and its construction material: waste rock. 
It must be kept in mind that the selection of options obeys the following aspects:

- The low solids content of the tailings discharged by the plant: $4 \%$. Such a low value makes it inevitable that a significant part of the water will be reclaimed in the vicinity of the plant, and, therefore, the option of only one thickener at the impoundment does not make economical sense given the high investment costs of transport pipelines for the tailings and reclaimed water and pumps for the recirculated water in addition to the operational cost of power for the pumping.

- The elevation of the plant and of the impoundment at its final capacity has a difference that limits the maximum slope of the tailings transport pipeline to a value that is less than $\sim 1.2 \%$. This implies that any tailings slurry with non-Newtonian behaviour will not have sufficient energy to flow by gravity only, requiring the aid of pumping. According to the results of the rheology tests, the alternative of only one thickener at the plant is the only case where pumping would be required to pump the tailings, flowing by gravity in all other cases.

- The quality of the water reclaimed in the iron process must comply with very strict norms in terms of solids in suspension. This implies the use of large quantities of flocculants or chemicals to achieve this objective. According to this requirement, the use of two thickeners means doubling the use of flocculent.

What follows is a summary of the technical-economical analysis of the different tailings thickening and transport alternatives between the plant and the Los Corralillos Impoundment.

\subsection{Alternative 1: Only one thickener located at the plant}

This alternative has a $50 \mathrm{~m}$ diameter, HCT-type thickener that delivers the tailings to a $70 \%$ concentration. For this concentration and a yield stress of $55 \mathrm{~Pa}$, the tailings flow in a laminar regime. In this type of flow, it is highly probable that a segregation of the tailings is produced, reason why the pumping considers $3+1$ positive displacement (PD) pumps of $400 \mathrm{HP}$ each. The tailings are transported to the tailings impoundment by a rubber lined steel pipeline of $\phi 12 "$ and of $5.5 \mathrm{~km}$ in length.

For this level of thickening, the deposited tailings free up a reduced amount of water (according to the sedimentation tests performed) that cannot be reclaimed and recirculated because it mostly evaporates or infiltrates during the deposition process.

\subsection{Alternative 2: Thickener at $40 \%$ at the plant and thickener at $70 \%$ at the impoundment}

This alternative has a $40 \mathrm{~m}$ diameter, HRT-type thickener at the plant that delivers the tailings at a $40 \%$ concentration. The thickened tailings are transported by gravity to the tailings impoundment by an HDPE pipeline of $450 \mathrm{~mm}$ in diameter and $5.5 \mathrm{~km}$ in length.

At the impoundment a $50 \mathrm{~m}$ diameter, HCT-type thickener is located that increases the solids percentage to $70 \%$. The water reclaimed from this second thickener is recirculated to the plant $(206 \mathrm{l} / \mathrm{s})$ by a pumping system constituted by $3+1200 \mathrm{HP}$ pumps and a $500 \mathrm{~mm}$ diameter HDPE pipeline, of variable thickness, depending on the pressure.

\subsection{Alternative 3: Thickener at 50\% at the plant and thickener at $70 \%$ at the impoundment}

This alternative has a $45 \mathrm{~m}$ diameter, HRT-type thickener at the plant that delivers the tailings at a $50 \%$ concentration. The thickened tailings are transported by gravity to the tailings impoundment by an HDPE pipeline of $400 \mathrm{~mm}$ in diameter and $5.5 \mathrm{~km}$ in length.

At the impoundment a $50 \mathrm{~m}$ diameter, HCT-type thickener is located that increases the solids percentage to $70 \%$. The water reclaimed from this second thickener is recirculated to the plant $(110 \mathrm{l} / \mathrm{s})$ by a pumping system constituted by $1+1300 \mathrm{HP}$ pumps and a $400 \mathrm{~mm}$ diameter HDPE pipeline, of variable thickness, depending on the pressure. 


\subsection{Alternative 4: Thickener at $60 \%$ at the plant and thickener at $70 \%$ at the impoundment}

This alternative has a $50 \mathrm{~m}$ diameter, HRT-type thickener at the plant that delivers the tailings at a $60 \%$ concentration. The thickened tailings are transported by pumping to the impoundment by $1+1$ centrifugal pumps of $450 \mathrm{HP}$ each and by a rubber lined steel pipeline of $305 \mathrm{~mm}$ diameter for the first $2.9 \mathrm{~km}$ of the transport and later by a $355 \mathrm{~mm}$ diameter HDPE pipeline for $2.6 \mathrm{~km}$ in length.

Also in this case, a $50 \mathrm{~m}$ diameter, HCT-type thickener is required at the impoundment that increases the concentration to $70 \%$. The water reclaimed from this second thickener $(46 \mathrm{l} / \mathrm{s})$ is pumped to the plant with $1+1$ pumps of $150 \mathrm{HP}$ each and a $280 \mathrm{~mm}$ diameter HDPE pipeline, of variable thickness, depending on the pressure.

The investment and operational costs for each alternative are summarised in the table below.

Table 2 Summary of costs (MUS\$) ${ }^{[1]}$

\begin{tabular}{llll}
\hline Case & Capital & Operation $^{[2]}$ & Total \\
\hline Alternative 1 & 37.47 & 34.61 & 72.10 \\
Alternative 2 & 29.27 & 33.31 & 62.59 \\
Alternative 3 & 27.64 & 32.43 & 60.07 \\
Alternative 4 & 28.99 & 33.27 & 62.26 \\
\hline Comparative values that include only the different items & & \\
[1] Values in millions of US Dollars. & & \\
[2] Values updated with a 10\% discount rate. & &
\end{tabular}

\subsection{Results of the comparative analysis of thickening and transport alternatives}

The alternative with the least investment costs is Alternative 3, with thickening to $50 \%$ in two stages, with a capital cost of MUS\$27.6. Including the operational costs, the result is a total cost of MUS\$60.1.

Alternative 1 with thickening at the plant is almost MUS\$10 more expensive than the alternatives with thickening in two stages (to 40 and 50\%), mainly due to the cost associated with the PD pumps.

If the alternative of thickening at the plant (1) is analysed with one of the two stages of thickening to $60 \%$, that considers pumping tailings with centrifugal pumps, the difference in cost is around MUS\$11. An important part of this difference is due to the costs of the PD pumps (valued at MUS\$9) and the steel pipeline (MUS\$3.6), the added value of which is above the increases of the intrinsic costs of the two stage thickening (double thickener, operational costs associated with the pumping of recirculated water).

In summary, based on the available background information, the most convenient option, from an economical point of view and previous considerations, for depositing the tailings with a $70 \%$ concentration in the Los Corralillos Impoundment, is that of thickening in two stages, with a primary thickening in the order of $50 \%$ at the plant and a secondary thickening at the impoundment at $70 \%$.

On the other hand, the operation with two thickeners allows for maintaining a conventional one at the plant and another one that allows the achievement of greater levels of thickening at the impoundment. In this manner, a technology that offers proven operational results is maintained at the plant, allowing the tailings transport to the impoundment where a second stage of thickening is performed. This thickening to a greater concentration than at the plant is undertaken near the impoundment, and leaves available at all times the alternative of depositing the partially thickened tailings directly into the impoundment should there be variations in the type of tailings or other condition that would prevent the expected additional thickening, without affecting the operation of the plant or the tailings transport.

\subsection{Considerations to make a decision}

- Level of thickening. 
The study was performed to manage tailings and deposit them at a $70 \%$ concentration. The selection of this number seemed convenient since it achieved two objectives: (i) ensure the reclaim of an important amount of water, and (ii) show the authorities that advanced technology was being applied. Due to the final cost of the solution of managing the tailings at $70 \%$, the question was raised whether $70 \%$ was the most convenient percentage, or, whether there exists an intermediate level of thickening between 60 and $70 \%$ that would be more beneficial from an economical point of view for the project. To this must be added the fact that the alternative with only one thickener is more expensive because of the requirement to use PD pumps, which could be eliminated by reducing the concentration in the tailings.

An analysis of this nature requires the revaluation of two aspects simultaneously:

- Water reclaim flow from the thickeners and impoundment.

- Tailings thickening and transport system.

The selection of the most convenient level of thickening must consider the costs of capital and operations associated with the works and facilities involved and the value of the greater flow of reclaimed water according to each case. Of all these costs, the most difficult to estimate is the cost of the greater flow of reclaimed water since it depends on the value that the mining company gives (i) to the risk, (ii) to the certainty of exercising the water rights, and (iii) to the alternative use of water.

Although this is a many faceted issue, it has to be approached in order to get the most convenient solution.

- Type of pumps.

In the study to thicken and transport the tailings, various configurations were analyzed. Intuitively, the most attractive seemed to be the one of concentrating the thickening (to 70\%) at the plant and transport the thickened tailings through pumps to the impoundment. In this manner, only one area of thickening exists and all the tailings process is concentrated near the vicinity of the plant. This option was not selected at the end since it required PD pumps (volumetric) to ensure the pumping of the tailings, pumps that have a very high cost that was higher than the costs associated with the number of thickeners and water reclaim systems.

The successive consultations with providers to find out whether it was possible to use centrifugal pumps (significantly more economical) instead of volumetric pumps yielded more or less a similar response:

- In principle, the centrifugal pumps have the capacity to pump tailings slurry with a yield stress of up to $100 \mathrm{~Pa}$, value much larger than what was determined for tailings at $70 \%$ concentration.

- But when it came time to guarantee the operation, the providers all stated that pump tests were required to ensure the operation of the pumps.

All of the above leads to the need for project management and particularly to coordination in multidisciplinary projects. In the case of a tailings impoundment, the coordination is always a key aspect since inevitably various companies participate. In this situation, the coordination of engineering firms, equipment manufacturers, and laboratories is required to align them to the objective of benefiting the project in each and all parts. To achieve this, it is necessary that the control and decision of the design of all the tailings management works remain in one firm that defines and manages the services of the manufacturing firms, laboratories, and associated engineering such that the final objective is not lost. The above implies that the laboratory and pilot tests need to be planned in a holistic manner to resolve all key aspects and not only what each provider looks at as his own business. 


\section{Conclusions}

Main comments and conclusions that have been derived from the Los Corralillos Impoundment Project are as follows:

- The general solution adopted consists of storing the tailings in an impoundment in the vicinity of the process plant. To contain the tailings, a dam is constructed with waste rock coming from the mining of the mine pit. The tailings are thickened until reaching a concentration of $70 \%$ by weight and are discharged from the rear of the impoundment. The thickening process is undertaken in two stages (with thickeners at the plant and at the impoundment) and the tailings are transported by pipeline and centrifugal pumps.

- This solution is technically feasible and ensures a high water reclaim from the tailings. The estimated water losses (make up water requirements) are 430 litres per tonne of tailings.

- The capability of the system to thicken to $70 \%$ concentration is backed up by tests from a pilot plant.

- The tailings pumping system between the plant and the impoundment is with centrifugal pumps which are a proven technology to manage tailings with concentrations of less than $60 \%$.

- From a risk point of view, the analysis performed concluded that the stage of the process in which the greatest amount of risks is presented is the operations, with all of them being technical risks for which control measures are proposed. Moreover, there are no critical or high risks once the control measures are established.

- Although the design complies with the safety and operational standards of a civil work of this nature, there are systems where optimisations could be performed. These systems are associated with the areas where the background information is limited or where the technology to be applied is at the limit of knowledge.

\section{References}

Arcadis, Information of studies (restricted data).

CETTEM (2007) Informe análisis reológico relaves Compañía Minera del Pacífico (reserved information).

Sofra, F. and Boger, D.V. (2001) Slope prediction for thickened tailings and pastes. Tailings and Mine Waste '01: Proceedings of the 8th International Conference on Tailings and Mine Waste, Fort Collins, Colorado, Balkema, Rotterdam, pp. 75-83. 